\title{
$\mathbf{J}|\mathbf{A}| \mathbf{C} \mid \mathbf{S}$ \\ COMMUNICATIONS
}

Published on Web 11/13/2002

\section{Dissections: Self-Assembled Aggregates That Spontaneously Reconfigure Their Structures When Their Environment Changes}

\author{
Chengde Mao, ${ }^{\dagger}$ Venkat R. Thalladi, ${ }^{\dagger}$ Daniel B. Wolfe, ${ }^{\dagger}$ Sue Whitesides, ${ }^{\ddagger}$ and \\ George M. Whitesides*,† \\ Department of Chemistry and Chemical Biology, Harvard University, 12 Oxford Street, \\ Cambridge, Massachusetts 02138, and School of Computer Science, McGill University, \\ 3480 University Street \#318, Montreal, Quebec H3A 2A7, Canada
}

Received July 31, 2002

This Communication demonstrates a physical realization of a type of mathematical construction called "geometric dissection". In mathematics, geometric dissection is the art of cutting a figure into pieces that can be rearranged to form another figure. ${ }^{1}$ Dissections were known in the third century AD; they have long fascinated puzzle fans and mathematicians. Dissections suggest a strategy for the design of adaptive structures. We have begun to explore physical realization of dissections using techniques already developed in millimeter-scale self-assembly, ${ }^{2}$ since the fabrication of components and the characterization of aggregates are easy when working at this scale. ${ }^{3}$ Here we describe systems of components in which self-assembly is caused by capillary interactions and in which the components have the capability of forming two or more assemblies with different structures. These components-millimeterscale plates having edges functionalized into hydrophobic and hydrophilic sets-float at the interface between an aqueous solution (to which sodium metatungstate can be added to increase its density) and a hydrophobic liquid (perfluorodecalin, PFD); the structure of the aggregate that is formed depends on the density of the aqueous phase.

Reconfiguration is triggered by changing the environment experienced by the plates from one where positive menisci dominate their self-assembly to one where negative menisci dominate ${ }^{2}$ (Figure 1). We use poly(dimethylsiloxane) (PDMS) doped with alumina in fabricating the components ${ }^{4}$ and adjust the density of these components to be $\rho=1.65 \mathrm{~g} / \mathrm{cm}^{3}$-a value intermediate between that of water $\left(\rho=1.00 \mathrm{~g} / \mathrm{cm}^{3}\right)$ and PFD $\left(\rho=1.91 \mathrm{~g} / \mathrm{cm}^{3}\right)$. The edges of the components are patterned into hydrophilic (L) or hydrophobic (B) sets. When these components float with their centers of gravity below the interface between water and PFD, the $\mathrm{L}$ faces develop large negative menisci. In these circumstances, capillary interactions between the $\mathrm{L}$ faces are strongly attractive and those between the $\mathrm{B}$ faces are negligible. ${ }^{5}$ When the density of the aqueous phase is increased to $\rho=1.60 \mathrm{~g} / \mathrm{cm}^{3}$ by adding sodium metatungstate $(0.16 \mathrm{M})$, the objects float with their centers of gravity above the interface and develop large positive menisci on $\mathrm{B}$ faces. In these circumstances, the capillary interactions between $B$ faces are strongly attractive, and those between $L$ faces are negligible. ${ }^{6}$ This strategy thus provides the basis for a set of components whose capillary interactions can be switched between different sets of faces to form two different structures, depending on their density relative to that of aqueous phase. Figure 1c sketches two assemblies that can be formed by $[1,3]$ square plates.

\footnotetext{
* Corresponding author. E-mail: gwhitesides@gmwgroup.harvard.edu.

Harvard University.

* McGill University.
}

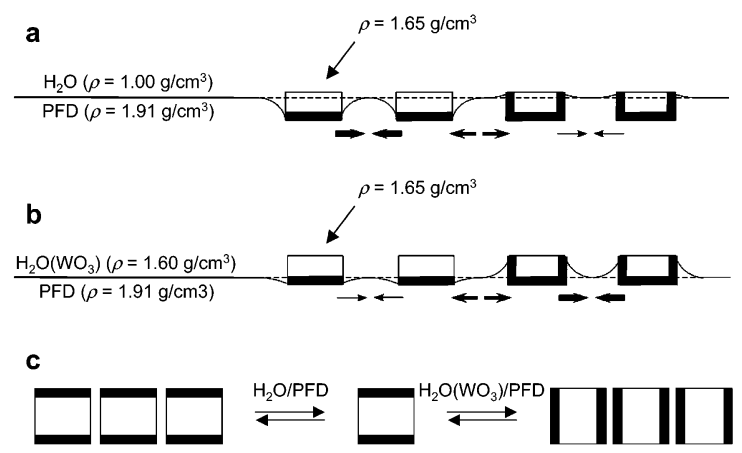

Figure 1. Strategy for making reconfigurable mesoscale self-assembled aggregates. ( $\mathrm{a}$ and $\mathrm{b}$ ) Side views of the self-assembling components fabricated in PDMS $/ \mathrm{Al}_{2} \mathrm{O}_{3}\left(\rho=1.65 \mathrm{~g} / \mathrm{cm}^{3}\right)$ at the liquid-liquid interface. Thin and thick lines on the components indicate hydrophilic (L) and hydrophobic (B) faces, respectively. (a) The components sink into the lower hydrophobic phase at the $\mathrm{H}_{2} \mathrm{O} / \mathrm{PFD}$ interface and develop large negative menisci and small positive menisci. (b) The same components when placed at the $\mathrm{H}_{2} \mathrm{O}\left(\mathrm{WO}_{3}\right) / \mathrm{PFD}$ interface rise into the upper hydrophilic phase and develop large positive menisci and small negative menisci. Like menisci attract and unlike menisci repel. ${ }^{2}$ The arrows suggest directions and relative strengths of lateral capillary forces. The thicker the arrows, the stronger the forces. (c) Schematic illustration of the self-assembly of [1,3] square components into linear aggregates.

Figure 2 illustrates four reconfigurable self-assembling systems having different structural complexity. In each, aggregates form through capillary bonds between $\mathrm{L}$ faces at the $\mathrm{H}_{2} \mathrm{O} / \mathrm{PFD}$ interface (Figures $2 \mathrm{a}, \mathrm{b}, \mathrm{c}$ ), and between $\mathrm{B}$ faces at the $\mathrm{H}_{2} \mathrm{O}\left(\mathrm{WO}_{3}\right) / \mathrm{PFD}$ interface (Figures 2a', $b^{\prime}, c^{\prime}$ ). We selected the target structures, shown in Figure 2, according to the following considerations: (1) there are two classes of surfaces in both interconverting structures: all "interior" surfaces become "exterior" surfaces during reconfiguration, and vice versa; (2) the structures contain a minimum number (here, one) of differently shaped components, to minimize the time required to find the minimum-energy configuration.

Figures $3 \mathrm{a}, 3 \mathrm{a}^{\prime}$, and $3 \mathrm{~b}, 3 \mathrm{~b}^{\prime}$ illustrate two systems that form similar target structures but the self-assembly is unconstrained in one system (a, $\left.a^{\prime}\right)$ and constrained in the other $\left(b, b^{\prime}\right)$. In the constrained system, we pierced holes in the components with a borer (diameter $\sim 400 \mu \mathrm{m}$ ) and tethered them by a cotton thread (diameter $\sim 100 \mu \mathrm{m})$. The thread did not interfere with the self-assembly of the components. Figures $3 c$ and $3 c^{\prime}$ illustrate the advantage of constrained self-assembly. Four components having different shapes were tethered and their faces functionalized into L and B sets as shown in the inset. Tethering limits the number of different ways 

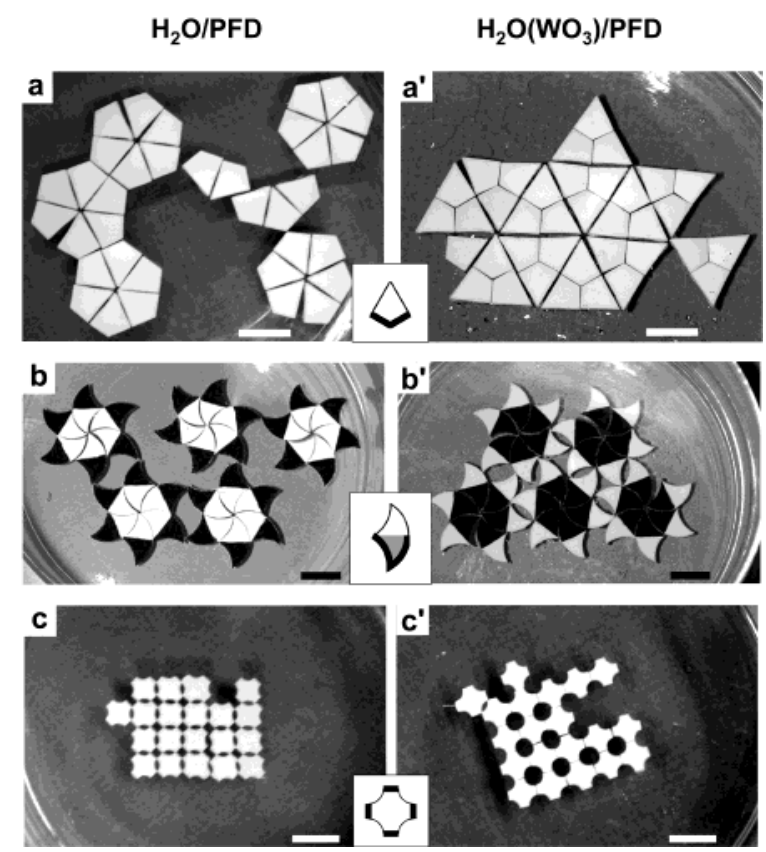

Figure 2. Dissections and reconfigurable self-assembly. The assemblies on the left are formed at the $\mathrm{H}_{2} \mathrm{O} / \mathrm{PFD}$ interface; those on the right are formed at the $\mathrm{H}_{2} \mathrm{O}\left(\mathrm{WO}_{3}\right) / \mathrm{PFD}$ interface. Thin and thick lines on the components (shown in the insets) indicate $\mathrm{L}$ and $\mathrm{B}$ faces, respectively. (a, a') Hexameric and trimeric aggregates formed from quadrilateral components. The number of components in the aggregates in a and a' are different. (b, $\left.b^{\prime}\right)$ Ratchet wheel structures formed from components with curved faces. The $\mathrm{L}$ and $\mathrm{B}$ faces are related by mirror symmetry (inset) and the aggregates in $\mathrm{b}$ and $\mathrm{b}^{\prime}$ have opposite chirality. (c, $\mathrm{c}^{\prime}$ ) Extended, periodic structures formed from components with curved $\mathrm{L}$ faces and flat $\mathrm{B}$ faces. The structure on the left has both hydrophilic and hydrophobic cavities; the one on the right has hydrophilic cavities only. Scale bars on all the images indicate 1 $\mathrm{cm}$.
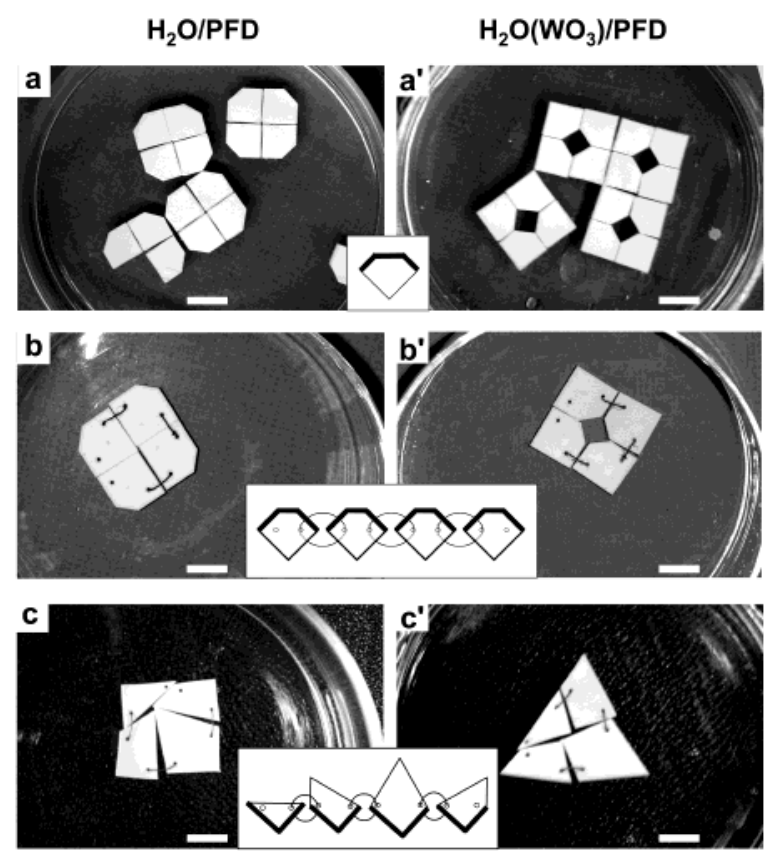

Figure 3. Unconstrained (a, $\left.a^{\prime}\right)$ and constrained (b, $\left.b^{\prime}\right)$ self-assembly of reconfigurable structures with closed-octagonal and open-square morphologies. The components in the open structure ( $a^{\prime}$ and $\left.b^{\prime}\right)$ do not use one of the three B faces. ( $c^{\prime}$ and $\left.c^{\prime}\right)$ Reconfigurable square- and triangle-shaped structures formed from constrained self-assembly. The assembly on the left uses seven L faces, while the one on the right uses eight B faces. Scale bars on all the images indicate $1 \mathrm{~cm}$. in which these components can recognize each other and results in the formation of assemblies with predetermined shapes (square or triangle). Tethering also results in a recognition pattern that is uncommon in unconstrained self-assembly: one face of a component assembling with two faces of two different components. When the same components shown in Figure $3 \mathrm{c}$ were allowed to selfassemble without the constraints provided by the tethers, they formed predominantly two- or three-component aggregates.

The strategy of changing the capillary forces by changing the density of aqueous phase provides one, easily implemented way to control mesoscale self-assembled structures. It will be interesting and useful to explore other means (for example, changing the interfacial free energy of the edges by changing the $\mathrm{pH}$ of the aqueous phase $\mathrm{e}^{7,8}$ or changing the effective density of a para- or ferromagnetic phase in a diamagnetic medium by changing the strength of an applied external magnetic field ${ }^{9}$ ) to switch selfassembled aggregates between different structures. Current methodology can be extended to components having lateral dimensions as small as $100 \mu \mathrm{m} ;{ }^{10}$ further miniaturization will require new methods.

Acknowledgment. This work was supported by the National Science Foundation (ECS-9729405 and CHE-9901358).

\section{References}

(1) Frederickson, G. N. Dissections: Plane \& Fancy; Cambridge University Press: Cambridge, 1997

(2) Bowden, N.; Weck, M.; Choi, I. S.; Whitesides, G. M. Acc. Chem. Res. 2001, 34, 231-238.

(3) The applications of mesoscale self-assembly include forming 3D microstructures [(a) Clark, T. D.; Tien, J.; Duffy, D. C.; Paul, K. E.; Whitesides, G. M. J. Am Chem. Soc. 2001, 123, 7677-7682]; forming electrical networks [(b) Gracias, D. H.; Tien, J.; Breen, T. L.; Hsu, C.; Whitesides, G. M. Science 2000, 289, 1170-1172. (c) Boncheva, M.; Gracias, D. H.; Jacobs, H. O.; Whitesides, G. M. Proc. Natl. Acad. Sci. U.S.A. 2002, 99 , 4937-4940. (d) Jacobs, H. O.; Tao, A. R.; Schwartz, A.; Gracias, D. H. Whitesides, G. M. Science 2002, 296, 323-325]; performing logical computations [(e) Rothemund, P. W. K. Proc. Natl. Acad. Sci. U.S.A. 2000, 97, 984-989]; and modeling materials [(f) Thalladi, V. R.; Schwartz, A.; Phend, J. N.; Hutchinson, J. W.; Whitesides, G. M. J. Am Chem. Soc. 2002, 124, 9912-9917].

(4) We followed the general experimental procedures described in our previous papers (Weck, M.; Choi, I. S.; Jeon, N. L.; Whitesides, G. M. J. Am. Chem. Soc. 2000, 122, 3546-3547. Choi, I. S.; Weck, M.; Jeon, N. L.; Whitesides, G. M. J. Am Chem. Soc. 2000, 122, 11997-11998) for the fabrication of components and their self-assembly. We fabricated components with density $1.65 \mathrm{~g} / \mathrm{cm}^{3}$ by doping alumina into poly(dimethylsiloxane) $\left(\mathrm{Al}_{2} \mathrm{O}_{3}-\mathrm{PDMS}\right)$ in 1:1 (w/w) proportions. Designated faces of the objects were made hydrophilic by oxidation in oxygen plasma. The density of the aqueous phase $\left[\mathrm{H}_{2} \mathrm{O}\left(\mathrm{WO}_{3}\right)\right]$ was adjusted to $1.60 \mathrm{~g} / \mathrm{cm}^{3}$ by making a $0.16 \mathrm{M}$ solution of sodium metatungstate $\left(3 \mathrm{Na}_{2} \mathrm{WO}_{4} \cdot 9 \mathrm{~W} 0_{3}\right.$. $\mathrm{H}_{2} \mathrm{O}$ ) in water. The objects were manually placed at the fluid-fluid interface in a Petri dish (diameter $=10 \mathrm{~cm}$ ) and swirled at a frequency of $0.9 \mathrm{~Hz}$ on an orbital shaker to allow the self-assembly to occur. Each self-assembly experiment was carried out at least 5 times, and the expected aggregates were formed in all the experiments. The overall yield varied between 93 and $100 \%$.

(5) Bowden, N.; Oliver, S. R. J.; Whitesides, G. M. J. Phys. Chem. B 2000 104, 2714-2724.

(6) Bowden, N.; Choi, I. S.; Grzybowski, B. A.; Whitesides, G. M. J. Am Chem. Soc. 1999, 121, 5373-5391.

(7) Wilson, M. D.; Whitesides, G. M. J. Am. Chem. Soc. 1988, 110, 87188719.

(8) Lee, T. R.; Carey, R. I.; Biebuyck, H. A.; Whitesides, G. M. Langmuir 1994, 10, 741-749.

(9) Deng, T.; Prentiss, M.; Whitesides, G. M. Appl. Phys. Lett. 2002, 80, 461-463.

(10) Bowden, N.; Arias, F.; Deng, T.; Whitesides, G. M. Langmuir 2001, 17, $1757-1765$.

JA021043D 